\title{
Using value of information methods to determine the optimal sample size for effectiveness trials of alcohol interventions for HIV-infected patients in East Africa
}

Lingfeng Li ${ }^{1}$, Jennifer Uyei ${ }^{1}$, Kimberly A. Nucifora ${ }^{1 *}$, Jason Kessler ${ }^{1}$, Elizabeth R. Stevens ${ }^{1}$, Kendall Bryant ${ }^{2}$ and R. Scott Braithwaite ${ }^{1}$

\begin{abstract}
Background: Unhealthy alcohol consumption exacerbates the HIV epidemic in East Africa. Potential benefits of new trials that test the effectiveness of alcohol interventions could not be evaluated by traditional sampling methods. Given the competition for health care resources in East Africa, this study aims to determine the optimal sample size given the opportunity cost of potentially re-allocating trial funds towards cost-effective alcohol treatments.

Methods: We used value of information methods to determine the optimal sample size by maximizing the expected net benefit of sampling for a hypothetical 2-arm intervention vs. control randomized trial, across ranges of policymaker's willingness-to-pay for the health benefit of an intervention. Probability distributions describing the relative likelihood of alternative trial results were imputed based on prior studies. In the base case, policymaker's willingness-to-pay was based on a simultaneously resource-constrained priority (routine HIV virological testing). Sensitivity analysis was performed for various willingness-to-pay thresholds and intervention durations.

Results: A new effectiveness trial accounting for the benefit of more precise decision-making on alcohol intervention implementation would benefit East Africa $\$ 67,000$ with the optimal sample size of 100 persons per arm under the base case willingness-to-pay threshold and intervention duration of 20 years. At both a conservative willingness-to-pay of $1 x$ GDP/capita and a high willingness-to-pay of $3 \times \mathrm{GDP} /$ capita for an additional health gain added by an alcohol intervention, a new trial was not recommended due to limited decision uncertainty. When intervention duration was 10 or 5 years, there was no return on investment across suggested willingness-to-pay thresholds.

Conclusions: Value of information methods could be used as an alternative approach to assist the efficient design of alcohol trials. If reducing unhealthy alcohol use is a long-term goal for HIV programs in East Africa, additional new trials with optimal sample sizes ranging from 100 to 250 persons per arm could save the opportunity cost of implementing less cost-effective alcohol strategies in HIV prevention. Otherwise, conducting a new trial is not recommended.
\end{abstract}

Keywords: Value of information, Optimal sample size, Alcohol intervention, HIV, East Africa

\footnotetext{
* Correspondence: kimberly.nucifora@nyumc.org

1 Department of Population Health, New York University School of Medicine,

227 East 30th Street, Floor 6, New York, NY 10016, USA

Full list of author information is available at the end of the article
}

(c) The Author(s). 2018 Open Access This article is distributed under the terms of the Creative Commons Attribution 4.0 International License (http://creativecommons.org/licenses/by/4.0/), which permits unrestricted use, distribution, and reproduction in any medium, provided you give appropriate credit to the original author(s) and the source, provide a link to the Creative Commons license, and indicate if changes were made. The Creative Commons Public Domain Dedication waiver (http://creativecommons.org/publicdomain/zero/1.0/) applies to the data made available in this article, unless otherwise stated. 


\section{Background}

Unhealthy alcohol consumption is common in East Africa [1] and multiple studies have shown that unhealthy alcohol consumption has exacerbated the HIV epidemic [2, 3]. For example, binge drinking and heavy alcohol consumption are associated with increased quantity of sexual partners, less likelihood of condom use, and increased commercial sex trade participation [4-8]. Furthermore, alcohol consumption also has a negative impact on adherence to antiretroviral therapies (ART) [7, 9-19]. Therefore, it is recommended that alcohol interventions that reduce harmful alcohol use among HIV infected patients in East Africa should be developed [3, 18], tested [19], and integrated as a part of HIV prevention and treatment programs $[2,6,7,20,21]$, especially considering the fact that sub-Saharan African countries still account for almost $70 \%$ of new infections in the global HIV epidemic [22]. Even though a few alcohol interventions, such as brief interventions [23-27] and cognitive-behavioral therapy [28], have shown positive results in reducing alcohol consumption or increasing alcohol abstinence in prior studies, the prior evidence on the effectiveness of alcohol interventions may not be sufficient to eliminate decision uncertainty with regard to the implementation of such interventions among HIV-infected patients. Therefore, new trials to gain additional information/evidence on the effectiveness of alcohol interventions are likely necessary. Note that we define prior information or prior evidence as the effectiveness of an alcohol intervention studied in prior trials and define additional information or additional evidence as the information that will be concluded from new trials.

A new trial could benefit HIV prevention and treatment programs in East Africa by providing additional evidence on alcohol interventions and thereby reducing decision uncertainty regarding the implementation of alcohol interventions. However, traditional sampling approaches do not account for the potential benefit of such trials since they are primarily based on determining the minimum sample size required to detect the desired intervention efficacy for given Type I and Type II error probabilities [29, 30]. Value of information (VOI) methodology was introduced as an alternative to the traditional sampling methods based on the notion that new trial information is valuable because the benefit of generating additional evidence may exceed the opportunity cost of potentially re-allocating trial funds towards treatments with uncertain cost-effectiveness [31, 32], which is critical in resource-limited settings. Specifically, VOI estimates optimal sample size by maximizing the expected net benefit of sampling (ENBS), which is the difference between the expected value of sample information (EVSI) from a new trial and the cost of sampling. Applying the VOI method to identify optimal sample size is more favorable in literature when trial information could yield clinical actionable inferences, and this method should be considered in the early phase of trial design [29, 30, 33, 34]. For example, VOI calculations have been previously applied to determine the optimal sample size for future trials on catheter securement devices to inform the decision-making on the adoption of the devices [30]. Another advantage of $\mathrm{VOI}$ is that it could pre-determine the necessity of conducting a new trial before the sample size calculation for a new trial. VOI could provide an upper bound estimation on the potential benefit of a new trial by determining the expected value of perfect information (EVPI) [33, 35]. Therefore, conducting a new trial would be necessary only when EVPI is positive. For example, Micieli et al. used EVPI to quantify the uncertainty on the adoption of left atrial appendage occlusion devices over dabigatran or warfarin in atrial fibrillation and concluded that additional trials on the relative efficacy of stroke reduction between the two strategies would be necessary due to high EVPI [34].

Accordingly, the objective of this study was to use VOI methods to determine the necessity of a new clinical trial that aims to address the effectiveness of alcohol interventions for HIV-infected patients in East Africa and to identify the optimal sample size for such trials if the necessary condition is met.

\section{Methods}

\section{Assumptions regarding hypothetical RCT}

To be concordant with a prior high evidence level alcohol study among HIV-infected patients in East Africa [36] and four recent National Institute of Health(NIH) funded RCTs in East Africa [37-40], we studied a hypothetical randomized-controlled trial (RCT) that aimed to investigate the effect size of an alcohol intervention for HIV infected patients in East Africa with following assumptions: (1) Participants will be equally randomized to an intervention arm and a control arm; (2) Participant eligibility criteria are hazardous or binge drinkers (score $\geq 3$ on the Alcohol Use Disorders Identification Test (AUDIT-C), a brief screening for heavy drinking and/or active alcohol abuse or dependence [36, 41-43]) and being ART-eligible or ART-initiated in the past 12 months; (3) The trial could be funded for 636 months; (4) Baseline trial costs, including program costs, marginal treatment costs, and reporting costs, were aggregated into a marginal cost per sample that was also based on the four RCTs (Table 1). Note that the primary interest of this work was to investigate evidence necessary to reduce uncertainty regarding the effect size of an alcohol intervention. The effect size was measured as the relative risk reduction of unhealthy alcohol consumption.

\section{Integrating prior information with new trial information: a Bayesian procedure}

Prior information provided by the alcohol trials that test the effect size of an alcohol intervention is defined as 
Table 1 Key model inputs

\begin{tabular}{|c|c|c|}
\hline Variables & Baseline values & Sources \\
\hline \multicolumn{3}{|l|}{ VOI variables } \\
\hline Expected prior effect size ${ }^{a}, \bar{e}$ & $45 \%$ & {$[28,36,45]$} \\
\hline Sample size for the prior study, $n_{0}$ & 75 & {$[28,36]$} \\
\hline Marginal cost per sample ${ }^{b}, \bar{c}$ & $\$ 1140$ & {$[37-40]$} \\
\hline \multicolumn{3}{|l|}{ HIV transmission variables } \\
\hline $\begin{array}{l}\text { Relative risk of unhealthy alcohol } \\
\text { use on risky sex }\end{array}$ & 1.29 & {$[45]$} \\
\hline $\begin{array}{l}\text { Relative risk of unhealthy alcohol } \\
\text { use on STIs }\end{array}$ & 1.72 & [45] \\
\hline $\begin{array}{l}\text { Relative risk of unhealthy alcohol } \\
\text { use on ART non-adherence }\end{array}$ & 2.33 & {$[45]$} \\
\hline
\end{tabular}

STIs Sexually Transmitted Infections

${ }^{a}$ Effect size was measured as relative risk reduction due to the implementation of an alcohol intervention for unhealthy alcohol drinkers in population

${ }^{\mathrm{b}}$ This summarizes program cost, treatment cost, and other costs

the information already available before a new trial, which may not be sufficient to support optimal decision-making. We specified the certitude regarding an alcohol intervention's effect size prior to additional information (e.g., "prior distribution") based on results of Papas and colleagues who evaluated a cognitive behavioral therapy-based intervention for HIV-positive outpatients with unhealthy alcohol use in Kenya [28, 36]. The intervention was based on social cognitive theory [44], and was designed to increase alcohol abstinence by teaching skills to mitigate substance use circumstances caused by stress or other problems. The intervention had been proven effective during the treatment and follow-up phases in Papas' study, and effect size information reported in the study was used to estimate the prior distribution below. Specifically, in prior distribution, $e_{0}$ is the intervention effect size sampled from the prior beta distribution; $\bar{e}$ is the expected prior effect size; and $n_{0}$ is sample size of the prior study (Table 1).

Prior distribution: $e_{0} \sim \operatorname{Beta}\left(n_{0} \bar{e}, n_{0}(1-\bar{e})\right)$.

If a new trial with sample size $n$ is initiated to gain additional information about the intervention effect size, in order to predict the sample statistics $\alpha_{D}$ for the new trial, we used a conjugate pair of the prior distribution to construct a predictive distribution. The predictive distribution is summarized below.

Predictive distribution: $\alpha_{D} \sim \operatorname{Binomial}\left(e_{0}, n\right)$

In order to utilize both of the prior and the new information on intervention effect sizes, an updated distribution was obtained by integrating the prior distribution and the predictive distribution through Bayesian Updating. $e_{1}$ is updated effect size.

Updated distribution: $e_{1} \sim \operatorname{Beta}\left(n_{0} \bar{e}+\alpha_{D}, n_{0}+n-n_{0} \bar{e}\right.$ $\left.-\alpha_{D}\right)$
Given a specific simple size $n$ for the new trial, we ran $I$ iterations to generate statistics $\alpha_{D}^{(i)}(i=1, \ldots, I)$. For each $\alpha_{D}^{(i)}$, we ran $J$ iterations to generate $e_{1}^{(j)} \mid \alpha_{D}^{(i)}(j=1$, $\ldots, J)$. We used a total number of one million $(I \times J)$ iterations to output a set of updated effect sizes to ensure the robustness of our VOI results. More details about the approach can be found elsewhere [31, 32].

\section{Incorporating the integrated information into a decision model of HIV treatment and prevention strategies}

As previously discussed, alcohol interventions among HIV infected patients might reduce HIV transmission and improve health, and additional information on the effectiveness of such interventions comes with the opportunity cost of not spending those funds on the interventions themselves, which are potentially cost-effective. We used a previously published and validated HIV model to test the impact of the updated distribution of intervention effect size $e_{1}$ on the decision of adopting $(s=1)$ versus not adopting $(s=0)$ the alcohol intervention $[45,46]$. The model outcomes necessary for the subsequent cost-effectiveness evaluations and VOI calculations were quality-adjusted life years $\operatorname{QALY}\left(s, e_{1}\right)$ and costs $\operatorname{cost}\left(s, e_{1}\right)$ for the intervention scenario $(s=1)$ and the null scenario $(s=0)$ respectively. A detailed description of the HIV model is reported elsewhere $[45,46]$. Briefly, the HIV model contains an HIV progression module and an HIV transmission module. The HIV progression module approximates the health outcomes by evaluating the change of CD4 cell counts and HIV-1 viral load for each HIV-infected individual. This module also simulates the effect of ART and takes the major causes of ART failure into account, such as ART non-adherence, non-adherence related genotypic resistance, and medication toxicity [46]. The individual-based HIV progression module interacts with a population-based compartmental HIV transmission module which simulates heterosexual transmission among the population in East Africa. The model compartments are differentiated based on health characteristics as well as behavioral risk characteristics. A hypothetical population switches compartments based on change to their health and behavior status. Probability of transmission is a function of multiple factors, including rate of acquiring new partners, duration of partnership, frequency of sexual contact within a partnership, and likelihood of condom use. The people who are in the compartments of unhealthy alcohol consumption were modeled as having these three major factors: increased risk of condom nonuse, increased risk of ART non-adherence, and increased STI prevalence (Table 1). The alcohol intervention reduces the HIV infection rate by transferring people from the compartments representing unhealthy alcohol consumption to those without unhealthy alcohol consumption. 
Assessing the value of information (VOI) added by a RCT In value of information (VOI) methods, expected value of perfect information (EVPI) represents an upper bound estimate on the potential benefit of a new trial if we assume new trial information would be perfect to help policymakers eliminate all decision uncertainty. Therefore, EVPI is used in economic evacuation to determine the necessity of conducting a new trial. Mathematically, it is the difference between the value of the decision made based on perfect information (e.g., after an RCT without bias and with infinite sample size) and the value of the decision made based on prior information (e.g., before a RCT) [31, 32]:

$$
E V P I=E_{e_{1}} \max _{r} N B\left(s, e_{1}\right)-\max _{r} E_{e_{1}} N B\left(s, e_{1}\right)
$$

A positive EVPI is a necessary condition for conducting a new RCT. Net benefit was calculated using the QALYs $\left(s, e_{1}\right)$ and costs $\left(s, e_{1}\right)$ generated by the HIV model using the following equation [31, 32]:

$$
N B\left(s, e_{1}\right)=\operatorname{QALY}\left(s, e_{1}\right) \times W T P-\operatorname{cost}\left(s, e_{1}\right)
$$

WTP is the decision maker's willingness-to-pay for incremental health benefit. The World Health Organization's (WHO) Choosing Interventions that are Cost-Effective (CHOICE) program recommends benchmarking willingness-to-pay (WTP) based on gross domestic product (GDP) per capita [47], in particular between 1 and 3 times the annual GDP per capita. Alternatively and in greater accord with economic theory, WTP may be inferred from a desired program that is not fully implemented because of resource constraints (e.g., routine viral load testing).

While EVPI estimates an upper bound benefit when information is perfectly known after a new trial (i.e., sample size of the new trial approaches infinity), expected value of sample information (EVSI) estimates the potential benefit of a new trial with a finite sample size. We then calculated the expected value of sample information (EVSI) which compares the net monetary benefit of a decision made with the updated information (e.g. after the RCT) and the benefit of a decision made with the prior information (e.g., before the RCT):

$$
E V S I=E_{\alpha_{D}} \max E_{e_{1} \mid \alpha_{D}} N B\left(s, e_{1}\right)-\max E_{e_{1}} N B\left(s, e_{1}\right)
$$

$E_{\alpha_{D}} \max E_{e_{1} \mid \alpha_{D}} N B\left(s, e_{1}\right)$ is the expected net benefit of the decision made based on the updated information (e.g., after the RCT), and $\max E_{e_{1}} N B\left(s, e_{1}\right)$ is the expected net benefit of the decision made with the prior information (e.g., before the RCT) [31, 32].

In additional to evaluating expected trial benefit, costs associated with conducting such a trial should be weighed against potential benefit in trial design. Expected net benefit of sampling (ENBS) values the expected net benefit of a new trial as the difference between the monetized expected value of sample information (EVSI) and the marginal investment of such a trial [31, 32]:

$$
E N B S=E V S I-C S=E V S I-\bar{c} \cdot n
$$

In the ENBS equation, CS is cost of sampling; $\bar{c}$ is marginal cost per sample (Table 1); and $n$ is the sample size of a trial. As sample size grows larger, the incremental certitude from information represented by EVSI grows smaller (i.e., diminishing returns) whereas the incremental cost of conducting the trial may not. As long as EVSI, or the value of conducting the new RCT, exceeds the corresponding study cost $(\mathrm{ENBS}>0)$, the return on investment would be positive. An optimal sample size could be obtained at which the expected net benefit of sampling (ENBS) is maximized.

\section{Sensitivity analysis}

Since ENBS is greatly influenced by policymakers' willingness-to-pay (WTP), we performed a sensitivity analysis to evaluate how optimal results change over a series of WTP benchmarks, where WTP was measured using the standard metric of US\$ per additional quality-adjusted life year (QALY), where QALY is a measure that aggregates additional quality and quantity of life. We also performed a sensitivity analysis across three intervention duration scenarios: long, medium, and short (20 years, 10 years, and 5 years respectively).

\section{Results}

\section{Cost-effectiveness acceptability based on prior information}

Given QALY and cost outcomes estimated by the HIV model, we applied cost-effectiveness acceptability curves [48] to identify where the decision uncertainty was greatest and how it varied by willingness-to-pay threshold. In Fig. 1a, when WTP threshold was greater than \$3200/QALY or smaller than \$900/QALY (shaded area), there would be no decision uncertainty with regard to choosing a more cost-effective strategy: prior evidence suggested that policymakers should adopt the intervention when WTP > \$3200/QALY or should not adopt the intervention when WTP $<$ \$900/QALY. In Fig. 1a, decision uncertainty existed in the unshaded area, and the greatest decision uncertainty arose when WTP $=\$ 1710$ / QALY. In this case, additional evidence from a new trial might be necessary to increase the certitude. Similarly, if we implement a study for 10 or 5 years (Fig. $1 \mathrm{~b}$ and c), the greatest uncertainty exists when WTP $=\$ 8000$ / QALY or \$31,000/QALY respectively. Given the distributions of decision uncertainty in unshaded areas in Fig. 1, EVPI can be used to quantify the consequence of 


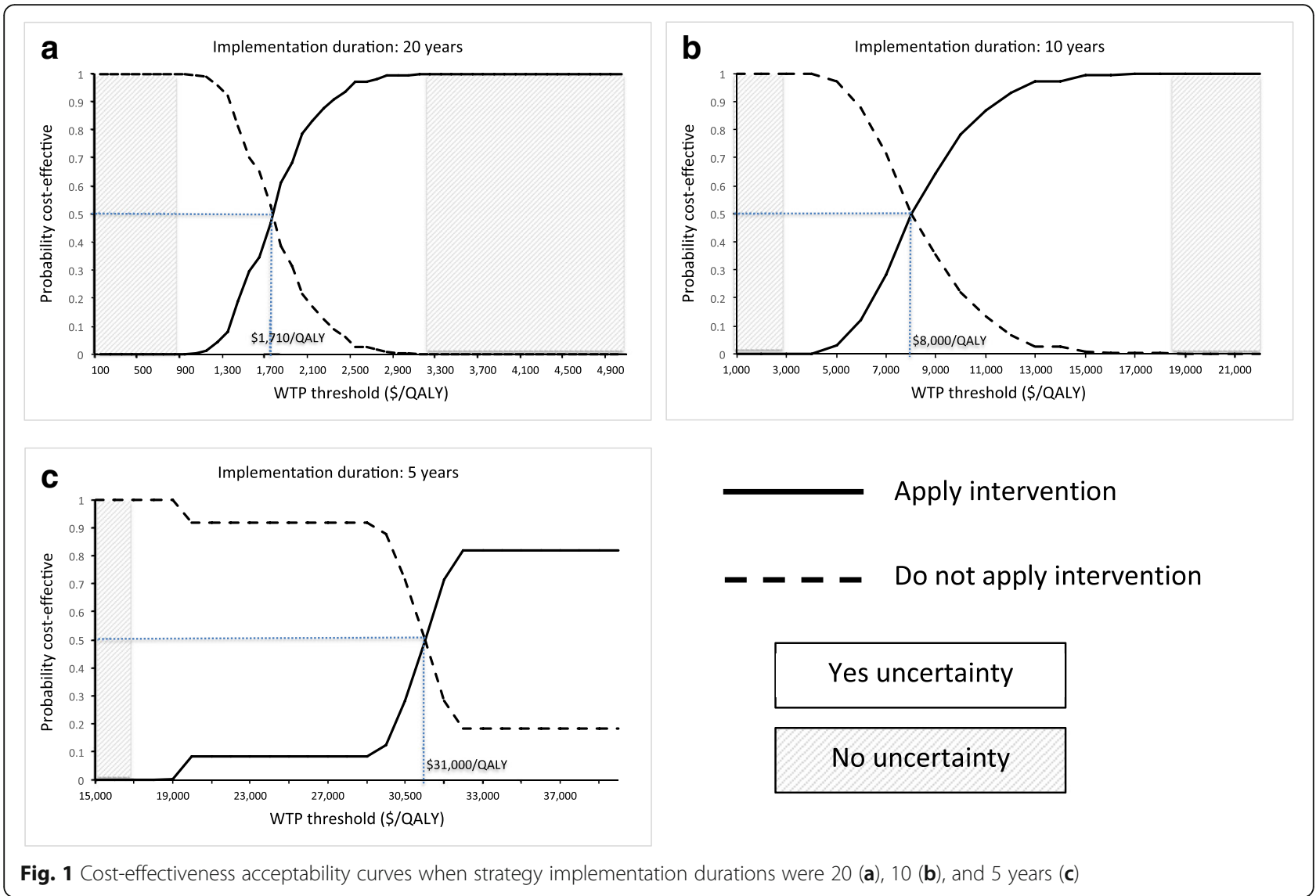

the decision uncertainty (or the health benefit of addressing the uncertainty) in a monetary format.

\section{Expected value of perfect information}

We used EVPI (Fig. 2) to quantify the uncertainties in Fig. 1, and the EVPI varied substantially over different WTPs and different durations of intervention implementation. When implementation duration was assumed to be 20 years, EVPI was maximized ( $\$ 14.8$ million) at a WTP of \$1710/QALY, well within the suggested range of WTPs for East Africa (\$1014/ QALY to \$3042/QALY), suggesting that a new RCT could yield valuable information. However, at shorter durations, the minimum WTP required to produce a positive EVSI fell outside the recommended range rendering the prospect of conducting a trial too expensive and not a good return on investment. For a duration of 10-years, EVPI was positive when WTP was greater than $\$ 4500 /$ QALY and maximized ( $\$ 5.8$ million) at a WTP of $\$ 8000 /$ QALY. For a duration of 5-years EVPI was positive when WTP was greater than $\$ 18,000 /$ QALY and maximized (\$3.4 million) at a WTP of $\$ 31,000 /$ QALY. Since EVPI is the upper bound estimate on the potential benefit of conducing a new trial, our EVPI results in Fig. 2 indicated that it might be worthwhile to conduct a new trial when the intervention implementation duration is 20 years. However, when intervention duration was set to 10 or 5 years, EVPI was zero across the WHO recommended range of WTPs for East Africa (\$1014/QALY to $\$ 3042 / \mathrm{QALY}$ ) [47], suggesting that a RCT should not be conducted under these two scenarios.

\section{Optimal sample size estimation - base case}

EVSI and ENBS were calculated to estimate an optimal sample size for a new study after the necessary condition was satisfied (EVPI $>0$ ). At baseline intervention duration of 20 years and baseline WTP equal to \$2473/ QALY, the incremental cost per QALY of implementing routine viral load testing for HIV-infected patients in East Africa, incremental cost of sampling for the trial grew larger whereas EVSI produced by the trial was diminished as the sample size of the trial grew larger in Fig. 3. Thus, the optimal sample size was found at the place where ENBS was maximized in Fig. 3. Specifically, the optimal sample size for the new RCT was 200 (100 per arm) and the corresponding maximum ENBS was $\$ 67$ thousand US dollars (Fig. 3) for the base case scenario. 


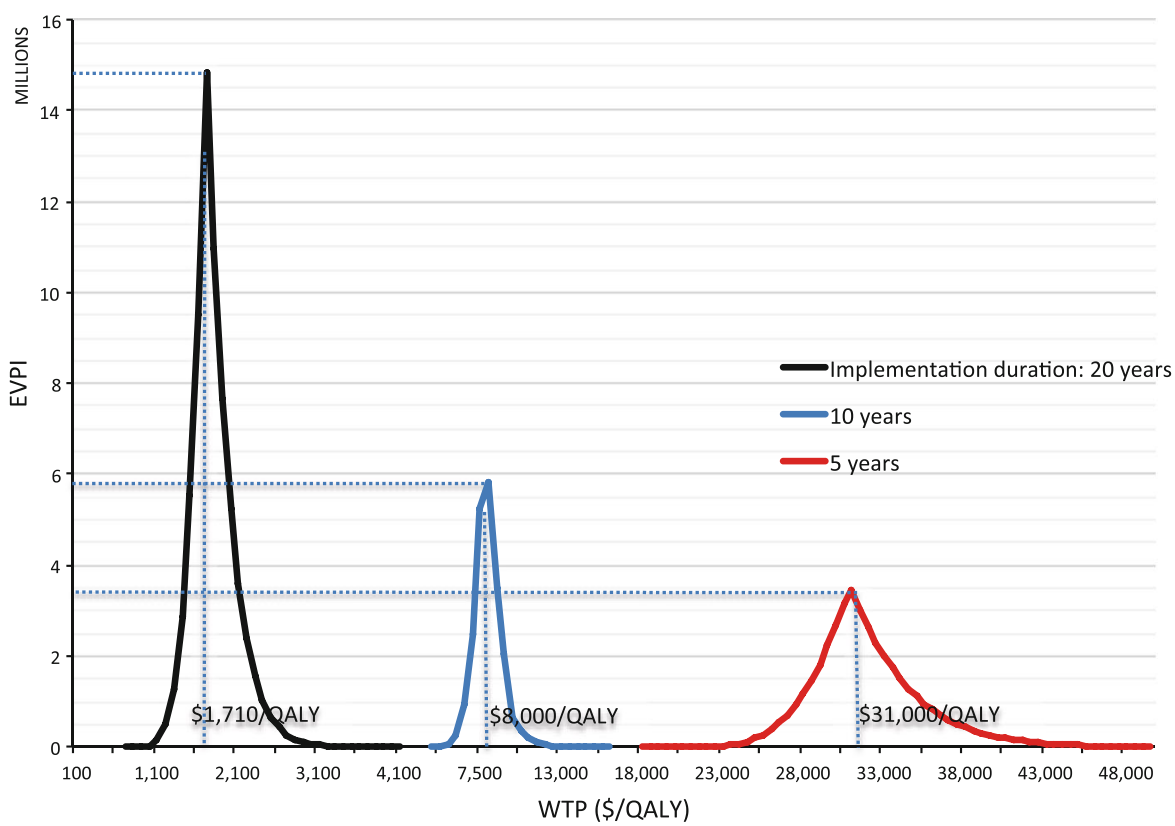

Fig. 2 EVPI curves when the alcohol intervention durations were 20, 10, and 5 years

\section{Optimal sample size estimation - sensitivity analysis}

For a scenario of using a conservative WTP (1 X GDP/ capita of East Africa, \$1014/QALY) and assuming an implementation duration of 20 years (Table 2), conducting a new trial was not recommended since the return on investment was negative $(\mathrm{ENBS}<0)$. Conducting a new trial was also not suggested even when policymakers were willing to pay more for an additional health gain and thereby using an upper bound WTP of 3 X GDP/capita (\$3042/ QALY) and also assuming an implementation duration of 20 years (Table 2). However, setting WTP equal to the incremental cost-effectiveness ratio (ICER) of the alcohol intervention (\$1710/QALY, within the lower and upper WTP bounds but distinct from our base case assumption), ENBS rose to more than $\$ 11$ million and corresponding optimal sample size reached 500 (250 per arm).

\section{Discussion}

Our results suggest that new RCTs to test interventions aimed at increasing alcohol abstinence among HIV-infected patients in East Africa are worthwhile investments assuming that policymakers intend to implement the intervention for a longer duration. Under such circumstances and assuming a WTP of a simultaneously resource-constrained

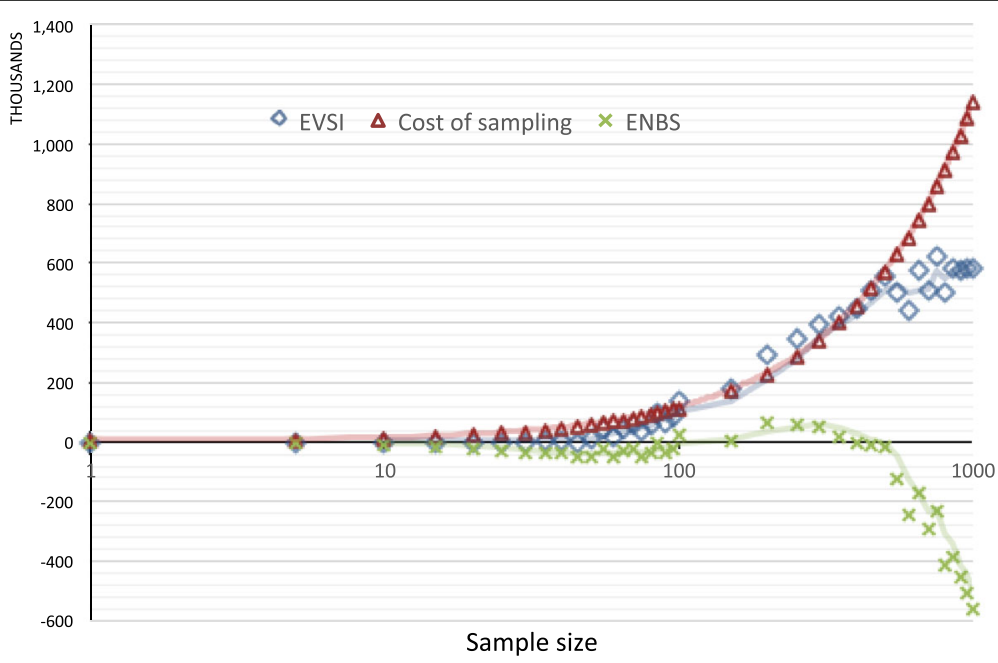

Fig. 3 EVSI, ENBS, and cost of sampling curves for the base case 
Table 2 Optimal sample sizes and maximum ENBS values for WTP benchmarks

\begin{tabular}{|c|c|c|c|c|c|}
\hline \multicolumn{4}{|l|}{ Scenarios } & \multicolumn{2}{|l|}{ Outcomes } \\
\hline WTP value (\$/QALY) & WTP benchmark & Source & $\begin{array}{l}\text { Intervention } \\
\text { duration (years) }\end{array}$ & $\begin{array}{l}\text { Optimal sample size } \\
\text { (each arm) }\end{array}$ & Maximum ENBS \\
\hline$\$ 1014$ & $1 \times$ GDP/capita & [49] & 20 & $N A^{a}$ & $<0$ \\
\hline$\$ 1124$ & $\begin{array}{l}\text { HIV laboratory monitory strategy if two ART } \\
\text { regimens are available }\end{array}$ & [46] & 20 & $N A^{a}$ & $<0$ \\
\hline$\$ 1770$ & ICER of 20 year alcohol intervention & - & 20 & 500 & $\$ 11,309,000$ \\
\hline$\$ 2473$ & $\begin{array}{l}\text { HIV laboratory monitory strategy if three ART } \\
\text { regimens are available (base case) }\end{array}$ & [46] & 20 & 200 & $\$ 67,400$ \\
\hline$\$ 3042$ & $3 \times$ GDP/capita & [49] & 20 & $N A^{a}$ & $<0$ \\
\hline$\$ 8000$ & ICER of 10 year alcohol intervention & - & 10 & 500 & $\$ 5,108,000$ \\
\hline$\$ 31,000$ & ICER of 5 year alcohol intervention & - & 5 & 240 & $\$ 2,949,000$ \\
\hline
\end{tabular}

${ }^{\mathrm{a}}$ Since return on investment for a new trial was negative (ENBS $<0$ ), conducting a new trial was not recommended for this scenario

priority (routine virological testing for HIV-infected patients), a new RCT with the optimal sample size of 200 (100 per arm) would yield an expected net benefit of $\$ 67$ thousand for East Africa.

When the alcohol intervention was assumed to be implemented for 10 or 5 years, an additional RCT would not yield information of favorable value across a plausible range of WTPs, and therefore our analyses suggest that it should not be conducted. In these scenarios, decision uncertainty was limited and standard care was always more cost-effective than the alcohol intervention given resource constraints in East Africa.

Notably, WTPs higher than the plausible range would result in RCTs having favorable value even with implementation durations of 10 years or 5 years. It is important to be mindful of this because even though the intervention duration is shorter, the opportunity cost of choosing a less cost-effective decision could still be high if decision makers are willing to pay a higher price for a QALY gain from the intervention.

The maximum ENBS for the intervention durations of 20 years, 10 years, and 5 years are $\$ 11$ million, $\$ 5$ million, and $\$ 3$ million respectively (Table 2 ), illustrating that the longer implementation of the alcohol intervention could result in far greater health gains. This is because (1) The benefit of the alcohol intervention is unlikely to be fully captured at a population level if the intervention implementation duration is short; and (2) The selection of other HIV strategies, other than the alcohol intervention, could result in more health gains in an East African population given the same healthcare research budget.

This study has several limitations. First, even though our VOI analyses and HIV simulation model are robust, there is still a stochastic noise that cannot be eliminated due to the considerable computational complexity. Second, due to lack of evidence on the effectiveness of alcohol intervention among HIV-infected patients in East Africa, the prior information was primarily based on one study [36], however, our VOI model structure allows for it to be updated if additional evidence becomes available. Third, decision uncertainty caused by cost variables was not addressed in this study.

In summary, we identified distributions of decision uncertainty regarding the adoption of alcohol interventions for HIV-infected patients in East Africa over a range of willingness-to-pay thresholds, quantified that uncertainty, and specified optimal sample sizes using a VOI approach rather than based on the minimum statistical power that is required to detect a pre-specified effect size. In situations in which trial information is likely to yield clinically actionable inferences with health importance, the VOI approach leads to larger sample sizes compared to power-based estimates, equivalent to requiring $p$-values below 0.05 . In situations in which trial information is unlikely to yield clinically actionable inferences with health importance, the approach leads to smaller sample sizes compared to power-based estimates, equivalent to allowing $\mathrm{p}$-values above 0.05 . Systematic application of this approach to trial design questions would be expected to produce increased health benefit from available resources for conducting research.

\section{Conclusions}

Value of information methods can be used to determine the optimal sample sizes of alcohol trials by reducing the risk of implementing less cost-effective alcohol strategies for HIV programs in East Africa, and they can be used as alternative approaches for the design of new trials when health care resources are limited. If reducing unhealthy alcohol use is a long-term goal for HIV programs in East Africa, additional 
new trials with optimal sample sizes ranging from 100 to 250 could save the opportunity cost of implementing less cost-effective alcohol strategies. Otherwise, conducting a new trial is not recommended.

\section{Abbreviations}

ART: Antiretroviral therapy; ENBS: Expected net benefit of sampling; EVPI: Expected value of perfect information; EVSI: Expected value of sample information; HIV: Human immunodeficiency virus; NIH: National Institute of Health; QALY: Quality-adjusted life year; RCT: Randomized controlled trial; STls: Sexually transmitted infections; VOI: Value of information; WTP: Willingness-to-pay

\section{Acknowledgements}

The VOI analysis in this study was achieved by using the High Performance Computing Facility in the Center for Health Informatics and Bioinformatics at New York University Langone Medical Center. This study is funded by National Institute on Alcohol Abuse and Alcoholism.

\section{Funding}

This study is supported by National Institute on Alcohol Abuse and Alcoholism.

\section{Availability of data and materials}

All data generated or analyzed during this study are included in this published article [28].

\section{Authors' contributions}

LL performed value of Information analysis, contributed research ideas, and drafted the manuscript. JU conducted literature review, performed value of information analysis, and contributed research ideas. KAN provided modeling support in HIV progression and transmission. JK provided clinical insights and guidance on HIV care and treatment. ERS supported data interpretation and manuscript revision. KB provided suggestions and research insights in alcohol research. RSB contributed research ideas and manuscript writing. All authors read and approved the final manuscript.

\section{Ethics approval and consent to participate}

Not applicable

\section{Consent for publication}

Not applicable

\section{Competing interests}

The authors declare that they have no competing interests.

\section{Publisher's Note}

Springer Nature remains neutral with regard to jurisdictional claims in published maps and institutional affiliations.

\section{Author details}

${ }^{1}$ Department of Population Health, New York University School of Medicine, 227 East 30th Street, Floor 6, New York, NY 10016, USA. ${ }^{2}$ National Institute on Alcohol Abuse and Alcoholism, National Institutes of Health, Bethesda, MD, USA

Received: 15 November 2017 Accepted: 4 July 2018

Published online: 31 July 2018

\section{References}

1. Global Status Report on Alcohol and Health. [http://www.who.int/substance abuse/publications/global_alcohol_report/en/]. Accessed 10 July 2018.

2. Sundararajan R, Wyatt MA, Woolf-King S, Pisarski EE, Emenyonu N, Muyindike WR, Hahn JA, Ware NC. Qualitative study of changes in alcohol use among HIV-infected adults entering care and treatment for HIV/AIDS in rural southwest Uganda. AIDS Behav. 2015;19(4):732-41.

3. Kiwanuka N, Ssetaala A, Nalutaaya A, Mpendo J, Wambuzi M, Nanvubya A Sigirenda S, Kitandwe PK, Nielsen LE, Balyegisawa A, et al. High incidence of HIV-1 infection in a general population of fishing communities around Lake Victoria, Uganda. PLoS One. 2014;9(5):e94932.

4. Woolf-King SE, Maisto SA. Alcohol use and high-risk sexual behavior in subSaharan Africa: a narrative review. Arch Sex Behav. 2011;40(1):17-42.
5. Kalichman SC, Simbayi LC, Kaufman M, Cain D, Jooste S. Alcohol use and sexual risks for HIV/AIDS in sub-Saharan Africa: systematic review of empirical findings. Prev Sci. 2007;8(2):141-51.

6. Chimoyi LA, Musenge E. Spatial analysis of factors associated with HIV infection among young people in Uganda, 2011. BMC Public Health. 2014;14:555.

7. Mbonye $\mathrm{M}$, Rutakumwa $\mathrm{R}$, Weiss $\mathrm{H}$, Seeley J. Alcohol consumption and high risk sexual behaviour among female sex workers in Uganda. Afr J AIDS Res. 2014;13(2):145-51.

8. Chersich MF, Bosire W, King'ola N, Temmerman M, Luchters S. Effects of hazardous and harmful alcohol use on HIV incidence and sexual behaviour: a cohort study of Kenyan female sex workers. Glob Health. 2014;10:22

9. Hendershot CS, Stoner SA, Pantalone DW, Simoni JM. Alcohol use and antiretroviral adherence: review and meta-analysis. J Acquir Immune Defic Syndr. 2009;52(2):180-202.

10. Bhat VG, Ramburuth $M$, Singh M, Titi O, Antony AP, Chiya L, Irusen EM, Mtyapi PP, Mofoka ME, Zibeke A, et al. Factors associated with poor adherence to anti-retroviral therapy in patients attending a rural health centre in South Africa. Eur J Clin Microbiol Infect Dis. 2010;29(8):947-53.

11. Do NT, Phiri K, Bussmann H, Gaolathe T, Marlink RG, Wester CW. Psychosocial factors affecting medication adherence among HIV-1 infected adults receiving combination antiretroviral therapy (CART) in Botswana. AIDS Res Hum Retrovir. 2010;26(6):685-91.

12. Kader R, Seedat S, Govender R, Koch JR, Parry CD. Hazardous and harmful use of alcohol and/or other drugs and health status among south African patients attending HIV clinics. AIDS Behav. 2014;18(3):525-34.

13. Haberer JE, Baeten JM, Campbell J, Wangisi J, Katabira E, Ronald A, Tumwesigye E, Psaros C, Safren SA, Ware NC, et al. Adherence to antiretroviral prophylaxis for HIV prevention: a substudy cohort within a clinical trial of serodiscordant couples in East Africa. PLoS Med. 2013;10(9):e1001511.

14. Van geertruyden JP, Woelk G, Mukumbi H, Ryder R, Colebunders R. Alcohol and antiretroviral adherence? What about Africa? J Acquir Immune Defic Syndr. 2010;54(4):e10.

15. Pefura-Yone EW, Soh E, Kengne AP, Balkissou AD, Kuaban C. Nonadherence to antiretroviral therapy in Yaounde: prevalence, determinants and the concordance of two screening criteria. J Infect Public Health. 2013;6(4):307-15.

16. Jaquet A, Ekouevi DK, Bashi J, Aboubakrine M, Messou E, Maiga M, Traore HA, Zannou MD, Guehi C, Ba-Gomis FO, et al. Alcohol use and nonadherence to antiretroviral therapy in HIV-infected patients in West Africa. Addiction. 2010;105(8):1416-21.

17. Naidoo P, Peltzer K, Louw J, Matseke G, McHunu G, Tutshana B. Predictors of tuberculosis (TB) and antiretroviral (ARV) medication non-adherence in public primary care patients in South Africa: a cross sectional study. BMC Public Health. 2013;13:396.

18. Denison JA, Koole O, Tsui S, Menten J, Torpey K, van Praag E, Mukadi YD, Colebunders R, Auld AF, Agolory S, et al. Incomplete adherence among treatment-experienced adults on antiretroviral therapy in Tanzania, Uganda and Zambia. AIDS. 2015:29(3):361-71.

19. Wandera B, Tumwesigye NM, Nankabirwa Jl, Kambugu AD, Parkes-Ratanshi R, Mafigiri DK, Kapiga S, Sethi AK. Alcohol consumption among HIV-infected persons in a large urban HIV Clinic in Kampala Uganda: a constellation of harmful behaviors. PLoS One. 2015;10(5):e0126236.

20. Hahn JA, Fatch R, Wanyenze RK, Baveewo S, Kamya MR, Bangsberg DR, Coates TJ. Decreases in self-reported alcohol consumption following HIV counseling and testing at Mulago hospital, Kampala, Uganda. BMC Infect Dis. 2014;14:403.

21. Medley A, Seth P, Pathak S, Howard AA, DeLuca N, Matiko E, Mwinyi A, Katuta F, Sheriff M, Makyao N, et al. Alcohol use and its association with HIV risk behaviors among a cohort of patients attending HIV clinical care in Tanzania, Kenya, and Namibia. AIDS Care. 2014;26(10):1288-97.

22. Fact sheet 2014. [http://www.unaids.org/sites/default/files/en/media/unaids/ contentassets/documents/factsheet/2014/20140716_FactSheet_en.pdf]. Accessed 10 July 2018.

23. WHO. A cross-national trial of brief interventions with heavy drinkers. Am J Public Health. 1996;86(7):948-55.

24. Babor TF, Higgins-Biddle JC. Alcohol screening and brief intervention: dissemination strategies for medical practice and public health. Addiction. 2000;95(5):677-86

25. Moyer A, Finney JW, Swearingen CE, Vergun P. Brief interventions for alcohol problems: a meta-analytic review of controlled investigations in 
treatment-seeking and non-treatment-seeking populations. Addiction. 2002;97(3):279-92

26. Kaner EF, Beyer F, Dickinson HO, Pienaar E, Campbell F, Schlesinger C, Heather $\mathrm{N}$, Saunders J, Burnand B. Effectiveness of brief alcohol interventions in primary care populations. Cochrane Database Syst Rev. 2007;2:CD004148.

27. L'Engle KL, Mwarogo P, Kingola N, Sinkele W, Weiner DH. A randomized controlled trial of a brief intervention to reduce alcohol use among female sex workers in Mombasa, Kenya. J Acquir Immune Defic Syndr. 2014;67(4):446-53.

28. Papas RK, Sidle JE, Martino S, Baliddawa JB, Songole R, Omolo OE, Gakinya BN, Mwaniki MM, Adina JO, Nafula T, et al. Systematic cultural adaptation of cognitive-behavioral therapy to reduce alcohol use among HIV-infected outpatients in western Kenya. AIDS Behav. 2010; 14(3):669-78.

29. Willan $A R$, Pinto EM. The value of information and optimal clinical trial design. Stat Med. 2005;24(12):1791-806.

30. Tuffaha HW, Reynolds H, Gordon LG, Rickard CM, Scuffham PA. Value of information analysis optimizing future trial design from a pilot study on catheter securement devices. Clin Trials. 2014;11(6):648-56.

31. Ades AE, Lu G, Claxton K. Expected value of sample information calculations in medical decision modeling. Med Decis Mak. 2004;24(2):207-27.

32. Briggs A, Claxton K, Sculpher M. Decision modelling for health economic evaluation. New York: Oxford University Press; 2006.

33. Claxton K, Neumann PJ, Araki S, Weinstein MC. Bayesian value-of-infomation analysis - an application to a policy model of Alzheimer's disease. Int J Technol Assess. 2001;17(1):38-55.

34. Micieli A, Bennell MC, Pham B, Krahn M, Singh SM, Wijeysundera HC Identifying future research priorities using value of information analyses: left atrial appendage occlusion devices in atrial fibrillation. J Am Heart Assoc. 2014;3(5):e001432.

35. Uyei J, Li LF, Braithwaite RS. Is more research always needed? Estimating optimal sample sizes for trials of retention in care interventions for HIVpositive East Africans. BMJ Glob Health. 2017;2(2):e000195.

36. Papas RK, Sidle JE, Gakinya BN, Baliddawa JB, Martino S, Mwaniki MM, Songole R, Omolo OE, Kamanda AM, Ayuku DO, et al. Treatment outcomes of a stage 1 cognitive-behavioral trial to reduce alcohol use among human immunodeficiency virus-infected out-patients in western Kenya. Addiction. 2011;106(12):2156-66.

37. Kurth A. Computerized counseling to promote positive prevention and HIV health in Kenya. In: NIH RePORT; 2012

38. Cohen M, Donenberg G, Nsanzimana S. Improving adherence among HIV+ Rwandan youth: a TI-CBT indigenous leader model. In: NIH RePORT: NIH; 2015. https://clinicaltrials.gov/ct2/show/NCT02464423.

39. Musoke $P$, Fowler MG. Using enhanced peer group strategies to support option B+ in Uganda. In: NIH RePORT: NIH; 2015. http://grantome.com/ grant/NIH/R01-HD080476-01.

40. Linnemayr S. Improving drug adherence among adolescents in Uganda using SMS reminders (RATA): ClinicalTrials.gov: NIH; 2014. https://clinicaltrials. gov/ct2/show/NCT02128087.

41. Gordon AJ, Maisto SA, McNeil M, Kraemer KL, Conigliaro RL, Kelley ME, Conigliaro J. Three questions can detect hazardous drinkers. J Fam Pract. 2001;50(4):313-20.

42. Saunders JB, Aasland OG, Babor TF, de la Fuente JR, Grant M. Development of the alcohol use disorders identification test (AUDIT): WHO collaborative project on early detection of persons with harmful alcohol consumption-II. Addiction. 1993;88(6):791-804.

43. Bush K, Kivlahan DR, McDonell MB, Finn SD, Bradley KA, Project ACQI. The AUDIT alcohol consumption questions (AUDIT-C) - an effective brief screening test for problem drinking. Arch Intern Med. 1998;158(16): 1789-95.

44. Bandura A. Citation classic - principles of behavior-modification. CC/Soc Behav Sci. 1979;29:10.

45. Braithwaite RS, Nucifora KA, Kessler J, Toohey C, Mentor SM, Uhler LM, Roberts MS, Bryant K. Impact of interventions targeting unhealthy alcohol use in Kenya on HIV transmission and AIDS-related deaths. Alcohol Clin Exp Res. 2014;38(4):1059-67.

46. Braithwaite RS, Nucifora KA, Yiannoutsos CT, Musick B, Kimaiyo S, Diero L, Bacon MC, Wools-Kaloustian K. Alternative antiretroviral monitoring strategies for HIV-infected patients in East Africa: opportunities to save more lives? J Int AIDS Soc. 2011;14:38.
47. Cost effectiveness and strategic planning (WHO-CHOICE). [http://www.who. int/choice/en/]. Accessed 10 July 2018.

48. van Hout BA, Al MJ, Gordon GS, Rutten FF. Costs, effects and C/E-ratios alongside a clinical trial. Health Econ. 1994;3(5):309-19.

49. EAC Facts \& Figures Report (2015). [http://www.eala.org/documents/view/ east-africancommunity-facts-and-figures-2015]. Accessed 10 July 2018

\section{Ready to submit your research? Choose BMC and benefit from:}

- fast, convenient online submission

- thorough peer review by experienced researchers in your field

- rapid publication on acceptance

- support for research data, including large and complex data types

- gold Open Access which fosters wider collaboration and increased citations

- maximum visibility for your research: over $100 \mathrm{M}$ website views per year

At BMC, research is always in progress.

Learn more biomedcentral.com/submissions 